\title{
Leaf-like Traumatic Fibroma in a Dentate Patient: An Unusual Case
}

\author{
Luiz HA Nascimento ${ }^{1}$, Tiago N Pinheiro ${ }^{2}$, Joel M Junior ${ }^{3}$, Gustavo C Albuquerque ${ }^{4}$, Marcelo V de Oliveira ${ }^{5}$, Valber B Martins ${ }^{6}$
}

\begin{abstract}
The leaf-like traumatic fibroma (LTF) is a benign fibrous lesion of the connective tissue. Its clinical characteristics feature a flattened pedicle aspect, adapting well to the palate, resembling a leaf. Its color is usually pink, similar to the adjacent epithelium. The growth is slow. The lesion may be larger than $2 \mathrm{~cm}$ in diameter. It may be present in the oral cavity for a long time. The LTF is commonly associated with poorly adapted removable complete or partial prostheses which cause a flattening of the lesion against the palate. This report presents an unusual case of an LTF in a dentate patient who did not use any type of prosthesis. Instead, the lesion was related to an injury caused by food trauma, which is an unusual etiology for this type of lesion. We reported the mechanical pressure of the tongue and the action of negative intraoral pressure, as possible modifying agents in causing the characteristic shape of the lesion. Treatment consists of conservative surgical removal since its recurrence is rare.
\end{abstract}

Keywords: Leaf-like fibroma, Palate, Wounds and injuries.

CODS Journal of Dentistry (2020): 10.5005/jp-journals-10063-0057

\section{INTRODUCTION}

Traumatic fibromas are the most common benign tumors of the oral cavity, with a prevalence of $1-2 \%$ in the general population. ${ }^{1}$ They develop from a hyperplastic tissue reaction, usually related to traumatic stimuli that are responsible for triggering inflammatory connective tissue reactions. ${ }^{2}$ These lesions have numerous forms, the most common being the nodular-shaped type. Leaflike traumatic fibroma (LTF) is so named because of its flattened pediculate aspect, presenting a leaf-like shape, which can interfere with chewing and speech, causing discomfort to the patient. ${ }^{3}$

The traumatic fibroma is traditionally asymptomatic. The lesion is usually pedunculated, with an average size of $7-8 \mathrm{~mm}$ in diameter but may be larger than $1-2 \mathrm{~cm} .{ }^{4}$ The surface of the mass is usually papillary, and the lesion may be clinically confused with a papilloma. The most commonly affected site is the oral mucosa along the line of occlusion. However, it can occur anywhere in the oral cavity including the labial mucosa and the tongue., ${ }^{3,5}$

The treatment of choice for fibromas is surgical excision of the lesion, with rare recurrence reported so far. ${ }^{6}$ Treatment alternatives include cryosurgery, which uses liquid nitrogen, and the strangulation technique. Cryosurgery is used in cases where patients are allergic to anesthetics or at high surgical risk. Other techniques used are electric and conventional scalpels. Some authors have proposed the application of penicillin $\mathrm{G}$ to the lesion, which they reported as having sclerosing effects on the lesion, thereby detaching it, and preventing recurrence. ${ }^{7,8}$

\section{Case Description}

A 38-year-old female melanoderma patient sought care complaining of "growth in the roof of the mouth". She did not present any systemic problems, denied being a smoker, and had no relevant family history. The patient related this growth to a food trauma injury at the site. On intraoral physical examination, a flat, pinkcolored, pedunculated lesion was observed. It was well-delimited, asymptomatic, resilient to palpation, and rough in texture. It has
1,3-6 Department of Cirurgia e Traumatologia Bucomaxilofacial, Universidade do Estado do Amazonas-UEA, Manaus, Amazonas, Brazil ${ }^{2}$ Department of Patologia Bucal, Universidade do Estado do Amazonas, Estomatologia e Cirurgia, Manaus, Amazonas, Brazil

Corresponding Author: Luiz HA Nascimento, Department of Cirurgia e Traumatologia Bucomaxilofacial, Universidade do Estado do Amazonas-UEA, Manaus, Amazonas, Brazil, Phone: +91 92988096222, e-mail: luisnasc2010@hotmail.com

How to cite this article: Nascimento LHA, Pinheiro TN, Junior JM, et al. Leaf-like Traumatic Fibroma in a Dentate Patient: An Unusual Case. CODS J Dent 2020;12(2):45-47.

Source of support: Nil

Conflict of interest: None

been present in the mouth for approximately 1 year, according to the patient's report. The lesion is located on the palatine mucosa, near teeth 26 and 27, and approximately $3 \mathrm{~cm}$ in diameter (Fig. 1).

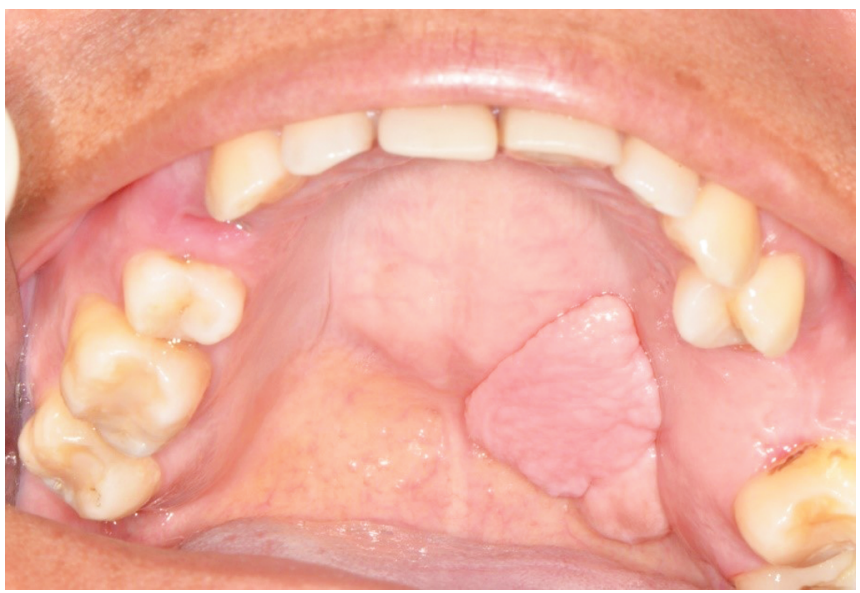

Fig. 1: Clinical aspect, showing mucosal-like, malleable lesion of a flattened shape, measuring about $3 \mathrm{~cm}$ in diameter 

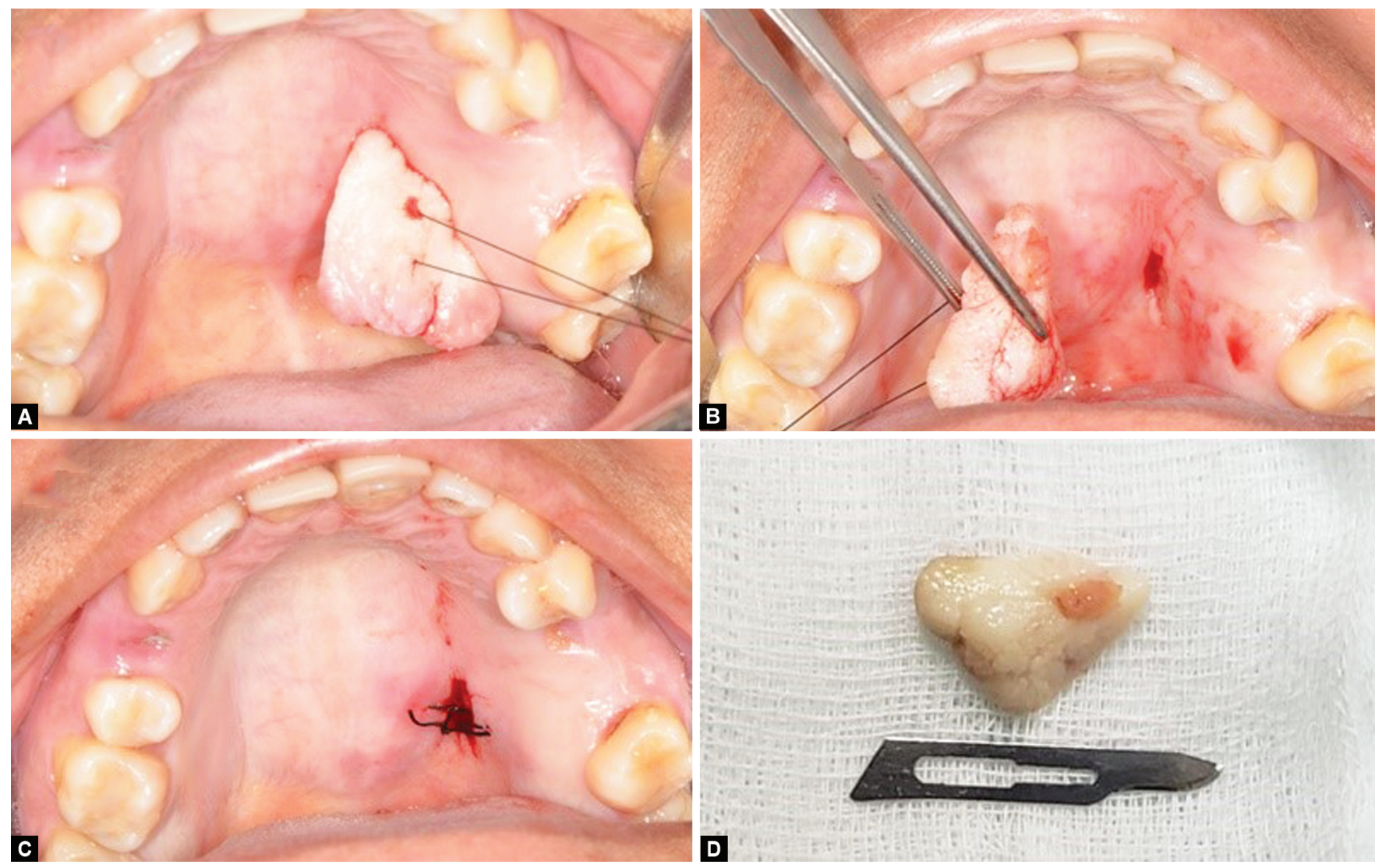

Figs $2 \mathrm{~A}$ to D: Raphea performed in order to better expose the base of the lesion for subsequent removal, followed by suture, and image of the removed surgical specimen

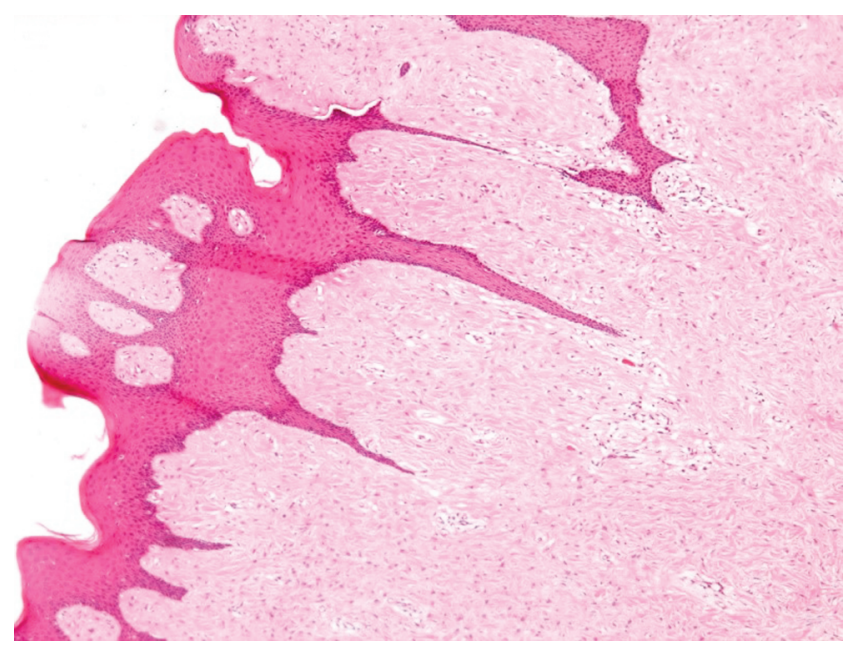

Fig. 3: Histological image. Microscopic sections revealed a fragment of oral mucosa coated with parakeratinized pavement stratified epithelium, showing pseudoepitheliomatous hyperplasia. The underlying unmodeled, well-bonded connective tissue was rich in voluminous core fibroblasts, sometimes star-shaped or fusiform, and eventually binucleated or trinucleated. A diagnosis of giant cell fibroma was confirmed

The patient did not use any dental prosthesis. A periapical X-ray of the region was exposed, which showed no localized alterations. Given the clinical findings, our presumptive diagnosis was traumatic fibroma or inflammatory fibrous hyperplasia (IFH).
Excisional biopsy of the lesion under local anesthesia was performed for the patient. At the beginning of the surgical procedure, a 4-0 silk suture was placed into the lesion to better visualize the base of the lesion. Using a number 15 scalpel blade, the incision was applied to the base of the lesion, and the margin extended $2 \mathrm{~mm}$ into healthy tissues. The wound was sutured with a 4-0 suture (Fig. 2). The hyperplasia tissue removed was referred for histopathological analysis. The histopathology findings reported that a fragment of the buccal mucosa was covered by stratified parakeratinized squamous epithelium with pseudoepitheliomatous hyperplasia and the underlying connective tissue was loose, unmodeled, well-collagenized, rich in large nucleated fibroblasts which were sometimes stellar or fusiform, and eventually binucleated or trinucleated. A diagnosis of giant cell fibroma was confirmed (Fig. 3). The patient was monitored at 7 and 30 days postoperatively. There was evidence of scar healing, with no signs of recurrence.

\section{Discussion}

The fibroma is a conjunctival tumor, originating from the proliferation of fibroblasts. It is a hypovascularized lesion coated by the oral mucosa, characterized by the presence of collagen and connective tissue. ${ }^{4}$ Its development takes place in response to local irritations or trauma, presenting as a nodular mass, with several morphological variations, one of which is the LTF, characterized by its flattened pedicle. ${ }^{3}$

These lesions have a higher prevalence in females between the second and the fifth decade of life. ${ }^{9,10}$ The case presented corroborates with the occurrence described in the literature. We 
can observe that the gender and age of the patient fit within the epidemiological pattern. Leaf-like traumatic fibroma usually arises from a local irritation, caused mostly by poorly adapted removable complete or partial prostheses, where a reactive growth of the tissue that develops under the prosthesis occurs. ${ }^{11}$ In the present very atypical case, the patient did not use any prosthesis and related the lesion to a fishbone that injured the site. It can be assumed that there was a traumatic stimulus in this reported case, resulting in tissue hyperplasia, to which the patient's tongue may have caused a negative compression of the lesion against the palate, thereby generating a flattened pedicle shape to the lesion. This case demonstrates that other factors can trigger the development of an LTF, such as oblique forces resulting from occlusal maladjustments and deleterious habits. ${ }^{12,13}$

The mechanical stimulus that causes tissue trauma can develop different types of pathological lesions, such as pyogenic granuloma, IFH, traumatic fibroma, and fibroepithelial polyp; and the differentiation of these lesions is related to the biological responses of the tissues, where cell maturation may be analyzed. 3,13 The LTF is a lesion that can be clinically confused with IFH. When we observe the lesions microscopically, the IFH is distinguished by a large number of collagen fibers and fibroblasts, in addition to an intense chronic inflammatory infiltrate present, ${ }^{11}$ while the traumatic fibroma is characterized by a rich dense hypovascularized collagen below the epithelial surface, with low fibroblast mitotic activity, and the presence of minimal inflammation except in dispersed submucosal areas. ${ }^{4}$ These observations were reported in the histopathological examination of the reported case. The reported lesion was differentiated by the presence of multiple large stellar-shaped nuclei and multinucleated fibroblasts. Thus, the GCF reported in the case is an intermediate lesion between IFH and fibroma. It presents a well-collagenized connective tissue rich in fibroblasts with epithelial projections toward the connective tissues, without a significant inflammatory process.

The treatment of choice for fibromas is surgical excision. ${ }^{14}$ The technique used should be individualized according to the characteristics and location of each fibroma. The usual anesthesia technique used for excision is a local infiltration around the lesion. In planning the excision, it is mandatory to remove the body and the base of the entire lesion. In addition, the exposed regions of the connective tissues at the surgical area require coverage and protection. This can be done by coating the tissues with surgical cement, or when the exposed tissues are muscular, as in cases of lingual and labial fibromas, the limits of the incision should be sutured. Some authors choose to let the surgical area heal by second intention. Removal of the fibrous hyperplastic areas can also be performed using electrosurgery, which is an option that provides the advantage of concurrent tissue excision and coagulation, thereby controlling bleeding at the same time. ${ }^{7}$ There are other treatment alternatives for these types of lesions, such as cryosurgery which uses liquid nitrogen and is very useful in cases where patients are at high risks for surgery or allergic to anesthetics. However, with cryotherapy, not being able to perform the histopathological studies of small samples is a limitation. ${ }^{7}$

The strangulation technique is proposed for resection of lesions $5 \mathrm{~mm}$ or less in ammeter, in the oral mucosa of the lips, cheeks, and the back of the tongue. ${ }^{6,7}$ It consists of using a surgical suture to surround the lesion with a knot, then applying firm pressure in such a way that the vascular supply reduces the lesion to a pale coloration, and the base of the lesion is incised by removing it from adjacent tissue using an $\mathrm{N}^{0} 15$ scalpel blade. The tissue bed appears slightly retracted without bleeding, so the procedure ends, and no suture is required. ${ }^{7}$ Some authors have proposed infiltration of the lesion with penicillin $\mathrm{G}$, reporting that it produces sclerosis of the lesion, thereby detaching it, and avoiding recurrence. ${ }^{7,15}$

The reported case was managed by means of excisional biopsy of the lesion, using a conventional scalpel. This technique was chosen because the lesion was easily accessible. Excision was performed using an elliptical incision with a perimeter of $2 \mathrm{~mm}$ of normal tissues. The therapeutic option selected for the reported case was based on the clinical characteristics of the lesion and the available conditions. ${ }^{7,8,14}$ This technique was effective for this case. ${ }^{7,8,14}$

\section{Final Considerations}

The present case is an atypical LTF in a patient who did not use any type of removable prosthesis. Being very rare, there are few reports in the literature. Its location, clinical appearance, and size were unusual. We reported the mechanical pressure of the tongue and the action of negative intraoral pressure, as possible modifying agents in causing the characteristic shape of the lesion.

\section{References}

1. Bagde $H$, Waghmare $A$, Savitha $B$, et al. Irritation fibroma: a case report. Int J Dent Clinics 2013;5:39-40.

2. Santos TS, Martins-Filho PRS, Pica MR, et al. Focal fibrous hyperplasia: a review of 193 cases. J Oral Maxillofac Pathol 2014;18(4):86-89. DOI: 10.4103/0973-029X.141328.

3. Mirtazapine $H$, Safi $Y$, Baharvand $M$, et al. Hindawi international journal of dentistry. Periphe Exophy Oral Lesi: Clin Decis Tree 2017;2017:1-19.

4. Kuriakose MA, Chakrabarti S, Cheong SC, et al. And neck tumors. Contempor Oral Med 2018. 25-27.

5. Vujhini SK, Reddy ES, Sudheer MVS, et al. Irritation fibroma of tongue: a case report. Int J Res Med Sci 2016;4:1272-1273. DOI: 10.18203/23206012.ijrms20160823.

6. Sreeia C, Vezhavendan N, Shabana E, et al. Recurrent peripheral odontogenic fibroma associated with basal cell budding. J Pharm Bioallied Sci 2014;6(5):204-207. DOI: 10.4103/0975-7406. 137470.

7. Correa PE, Arias Mendieta S. Resección de fibroma en mucosa oral. Tecnica del estrangulamiento. Rev CES Odontol 2016;29(1):82-87. DOI: 10.21615/cesodon.29.1.8

8. Borras MT, Delgado-Molina E, Berini-Aytés L, et al. Exeresis de las lesiones hiperplásicas de la cavidad bucal. Estudio retrospectivo de 128 casos. Med Oral Patol Oral Cir Buca 2005;10:151-162.

9. Esmeili T, Lozada-Nur F, Epstein J. Common benign oral soft tissue masses. Dent Clin North Am 2005;49(1):23-40. DOI: 10.1016/j. cden.2004.07.001.

10. Braga MM, Carvalho ALG, Vasconcelos MCP, et al. Giant cell fibroma: a case report. J Clin Pediatr Dent 2006;30(3):261-264. DOI: 10.17796/ jcpd.30.3.j784203n931w3x6j.

11. Veena $\mathrm{K}$, Jagadishchandra $\mathrm{H}$, Sequria J, et al. An extensive dentureinduced hyperplasia of maxilla. Ann Med Health Sci Res 2013;3(5):7-9. DOI: $10.4103 / 2141-9248.121208$.

12. Canger EM, Celenk P, Kayipmaz S. Denture-related hyperplasia: a clinical study of a Turkish population group. Braz Dent J 2009;20(3):243-248. DOI: 10.1590/S0103-64402009000300013.

13. Carvalho FK, Pinheiro TN, Arid J, et al. Trauma-induced giant pyogenic granuloma in the upper lip. J Dent Child 2015;82:168-170.

14. Rossmann JA. Reactive lesions of the gingiva: diagnosis and treatment options. Open Pathol J 2011;5(1):23-32. DOI: 10.2174/1874375701105010023.

15. Villavicencio VF, Luengo FJ, Hernçndez MM, et al. Fibroma de células gigantes en lactante mayor. Reporte de un caso. Int J Odontostomat 2018;12(2):93-96. DOI: 10.4067/S0718-381X2018000200093. 